\title{
Analysis of Brassica oleracea early stage abiotic stress responses reveals tolerance in multiple crop types and for multiple sources of stress
}

by Beacham, A.M., Hand, P., Pink, D.A.C. and Monaghan, J.M.

Copyright, Publisher and Additional Information: This is the author accepted manuscript. The final published version (version of record) is available online via Wiley.

This article may be used for non-commercial purposes in accordance with Wiley Terms and Conditions for Self-Archiving.

DOI: https://doi.org/ 10.1002/jsfa.8411 


\title{
Analysis of Brassica oleracea early stage abiotic stress responses reveals tolerance in
}

multiple crop types and for multiple sources of stress

\section{Brassica oleracea abiotic stress tolerance}

\author{
AUTHORS \\ Andrew M Beacham ${ }^{\mathrm{a}}$, Paul Hand, David A C Pink and James M Monaghan \\ Fresh Produce Research Centre, Crop and Environment Sciences Department, Harper Adams \\ University, Edgmond, Shropshire, TF10 8NB, UK \\ ${ }^{a}$ Author for correspondence: abeacham@harper-adams.ac.uk
}

\begin{abstract}
BACKGROUND: Brassica oleracea includes a number of important crop types such as cabbage, cauliflower, broccoli and kale. Current climate conditions and weather patterns are causing significant losses in these crops, meaning that new cultivars with improved tolerance of one or more abiotic stress types must be sought. We assayed genetically fixed B. oleracea lines belonging to a Diversity Fixed Foundation Set (DFFS) for their response to seedling stageimposed drought, flood, salinity, heat and cold stress. RESULTS: Significant $(P \leq 0.05)$ variation in stress tolerance response was found for each stress, for each of four measured variables (relative fresh weight, relative dry weight, relative leaf number and relative plant height). Lines tolerant to multiple stresses were found to belong to several different crop types. There was no overall correlation between the responses to the different stresses CONCLUSIONS: Abiotic stress tolerance was identified in multiple B. oleracea crop types with some lines exhibiting resistance to multiple stresses. For each stress, no one crop type
\end{abstract}

This article has been accepted for publication and undergone full peer review but has not been through the copyediting, typesetting, pagination and proofreading process, which may lead to differences between this version and the Version of Record. Please cite this article as doi: $10.1002 /$ jsfa.8411 
appeared significantly more or less tolerant than others. The results are promising for the development of more environmentally robust lines of different $B$. oleracea crops by identifying tolerant material and highlighting the relationship between responses to different stresses.

\section{KEYWORDS}

Brassica oleracea, abiotic stress, drought, flood, salinity, heat, cold

\section{INTRODUCTION}

Climatic uncertainty and escalating frequency of drought, flooding and other sources of abiotic stress are leading to large scale losses and unpredictability in production scheduling in a large range of fresh produce crops. As such, improving the environmental tolerance of crops is becoming of increasing importance. ${ }^{1}$ The selection of stress-tolerant lines is therefore important for providing novel genetic material for breeding programmes that will produce cultivars with future durability. Tolerance towards one type of stress would be beneficial but the identification of lines showing resistance to multiple stresses would be additionally advantageous in developing climatically resilient varieties.

Brassica oleracea represents a group of important food crops that includes cabbage (B. oleracea L. var. capitata), cauliflower (var. botrytis), broccoli (var. italica), kale (var. acephala), Chinese kale (var. alboglabra), Brussels sprouts (var. gemmifera) and kohlrabi (var. gongylodes) amongst others. B. oleracea cultivars are generally considered to be cool-season crops and therefore would be expected to suffer during periods of higher temperature, ${ }^{2}$ but they may also be sensitive to extremes of drought, waterlogging, salinity, cold or other sources of abiotic stress. 
Temperature during the growth period has been shown to impact upon the growth of $B$. oleracea crops. For example, cabbage plants have been found to show reduced disease tolerance and lower yields at high temperatures. ${ }^{3}$ Both low and high temperatures have been reported to affect stomatal conductance and fresh weight in cabbage and kale, but with kale appearing more susceptible to changes in air temperature than cabbage. ${ }^{4}$

Previous studies have highlighted the requirement for correct water balance in maximising $B$. oleracea productivity. Drought stress in cauliflower led to reduced seed germination, shoot and root length and biomass, ${ }^{5}$ stomatal conductance, transpiration, curd growth and dry matter. ${ }^{6-7}$ In Chinese kale, both water deficit and waterlogging led to reduced leaf area, fresh and dry weight and leaf number, with drought leading to darker leaves and closed stomata. ${ }^{8}$ Short periods of waterlogging stress lead to cultivar differences in cauliflower and broccoli in variables including heading percentage, yield per unit area, root dry weight, protein expression and growth scores. ${ }^{9-}$

${ }^{11}$ High salinity has been found to decrease shoot and root length, dry weight and fresh weight in cauliflower, ${ }^{12-15}$ broccoli,${ }^{14}$ kale ${ }^{16}$ and cabbage. ${ }^{17-20}$

This study analysed the drought, flooding, salinity, heat and cold stress tolerance of B. oleracea lines of the Vegetable Genetic Improvement Network (VeGIN) B. oleracea Diversity Fixed Foundation Set (DFFS). This set represents a group of genetically fixed, double haploid (DH) lines which have been chosen to maximise both genetic and morphological variability and have been obtained from a wide range of geographical sources. The group of lines tested included cabbage (B. oleracea L. var. capitata), cauliflower (var. botrytis), broccoli (var. italica), kale (var. acephala), Chinese kale (var. alboglabra) and kohlrabi (var. gongylodes). No DH lines of Brussels sprouts (var. gemmifera) were available at the time of the study. These plants have been developed as $\mathrm{DH}$ lines to eliminate the heterogeneity and heterozygosity commonly encountered with genebank lines, allowing the same genotype to be tested against different stresses. To our knowledge this is the first time that a fixed diversity set has been screened against multiple stresses in this manner. 
The establishment of Brassica transplants in the field is essential for successful crop production. Adverse conditions early in growth can lead to negative effects on crop development and ultimately to decreased crop uniformity, delays in harvest time and reductions in yield. Because of this, the lines were subjected to short periods of abiotic stress at the 3-4 true leaf stage and their subsequent growth assayed. The stresses were chosen to reflect the range of transient abiotic stress that may be experienced by young plants, particularly following transplanting into the field. The treatments represented, a period of water stress due to either low or high levels of water in the soil at planting, limited seawater ingress, heat and cold stress. The stress methodologies were chosen as a balance between the ability to rapidly screen large number of seedlings and imposing a stress that as far as possible represents stress conditions that may be encountered in the field. The study represents the use of a rapid screening methodology which focuses on the growth responses of the lines, a key trait both for growers and for highlighting material for further investigation and use in the breeding of varieties with increased stress tolerance. We hypothesised 1) that lines of the DFFS would exhibit a range of responses to the different stresses, exhibiting different degrees of tolerance to each stress and that 2) some lines may exhibit tolerance to multiple stresses. The study also investigated the relationship between responses to the different stresses and the importance of crop type in abiotic stress tolerance. Given the different growth habits of the crop types, we further hypothesised that 3) the different crop types contained within B. oleracea would respond differently to the different stresses.

This paper demonstrates the value of the DFFS - which allows the same genotype to be screened against different environments in a controlled manner and therefore allows assessment of the genetic variation in stress response within B. oleracea - the DFFS is derived form a core collection representing the variation held in gene bank collections and is a unique resource which allows screening of fixed genotypes in varying environmental conditions. 


\section{EXPERIMENTAL}

\section{Plant Growth}

Lines of the Vegetable Genetic Improvement Network (VeGIN) B. oleracea Diversity Fixed Foundation Set (DFFS, Warwick Crop Centre, UK) plus the commercially available cabbage 'Greyhound' and kale 'Nero di Toscana' were used in this study. All lines were genetically fixed by the double haploid (DH) method with the exception of 'Greyhound' (line G, $B$. oleracea var. capitata), 'Nero di Toscana' (line N, B. oleracea var. acephala), CO7037 and C07077 (lines 59 and 60, both derived from cross between a B. oleracea var. alboglabra $\mathrm{x}$ italica parent and a var. capitata parent). These non-DH lines were included for comparison due to being used as part of a group of lines, along with a selection of $\mathrm{DH}$ lines, to optimise the conditions for the assays. Drought, flooding and salinity stress were tested initially for 65 lines. The set of lines used included six B. oleracea var. acephala (kale) lines, six var. alboglabra (Chinese kale), one var. alboglabra x italica, sixteen var. botrytis (cauliflower), seven var. capitata (cabbage), two var, costata (Tronchuda cabbage), two hybrid lines derived from cross between a var. alboglabra x italica parent and a var. capitata parent, two var. gongylodes (kohlrabi) and twenty three var. italica (broccoli). A selection of 20 of these lines was then assayed for heat and cold stress tolerance. This subset of lines included two B. oleracea var. alboglabra, four var. botrytis, six var. capitata and eight var italica. Each experiment was replicated three times over time. Plants were grown in a glasshouse at Harper Adams University, Shropshire UK with an average temperature for the first set of experiments of $16.6^{\circ} \mathrm{C}$ (minimum $6.0^{\circ} \mathrm{C}$, maximum $31.3^{\circ} \mathrm{C}$ ) and an average temperature over the second set of experiments of $16.0^{\circ} \mathrm{C}$ (minimum $4.1^{\circ} \mathrm{C}$, maximum $31.3^{\circ} \mathrm{C}$ ). Supplementary lighting set to a 16 hour day was provided where needed. Plants were sown and grown in ' 345 ' module trays, watering as required, until the lines possessed 3-4 true leaves.

Stress Treatments

This article is protected by copyright. All rights reserved. 
Short term stress treatments were imposed to provide a stress shock to the B. oleracea seedlings at the three-four true leaf stage. This approach aimed to reflect stresses that occur upon the planting of $B$. oleracea transplants into the field. The need to provide a rapid screening methodology that would allow large numbers of plants to be treated at an early stage was balanced against the provision of a stress reflecting a real-life situation. We consider that such a rapid screening method is useful for initial identification of promising lines that can subsequently be assayed for responses to longer term stress impositions. The plants were divided into separate module trays (one plant per line per tray), with one tray used per stress imposed, plus a control tray. The control tray continued to be watered as required. For the drought stress experiment, watering was withheld for two consecutive days. For the flood stress experiment, the module trays were placed in a tray filled with water such that the water level was $5 \mathrm{~mm}$ below the top of the module tray, saturating the root zones, and grown for six consecutive days. For the salinity stress experiment, the module trays were dipped for $15 \mathrm{~s}$ daily in a tray filled with 21 of $30 \mathrm{~g} \mathrm{l}^{-1} \mathrm{NaCl}$ solution for six consecutive days. For the heat stress experiment, the tray was watered as normal then placed in a Fitotron growth chamber (Weiss Technik, Loughborough, UK) at $38^{\circ} \mathrm{C}, 60 \%$ relative humidity for $7 \mathrm{hrs}$ with supplementary lighting during the light phase. For the cold stress experiment, the tray was placed at $-20^{\circ} \mathrm{C}$ for 2 minutes in the dark for three consecutive days. For each stress experiment, after the end of the stress period, trays were watered as required as per the control until all stress regimes were complete. Seedlings were then planted into $7 \mathrm{~cm}$ round pots equally filled with Levington M2 compost (ICL Ltd, Ipswich, UK) and placed in a split-plot randomised arrangement on top of empty module trays to allow drainage. The pots were then watered to saturation as required (usually 3 times per week), with the modules allowing the drainage of excess water. The plants were grown for 20 further days until destructive sampling.

\section{Measurements and analysis}

At the end of the experiment, the number of true leaves on each plant was counted and the overall height of each plant was measured. The fresh and dry weight of each plant was recorded

\section{This article is protected by copyright. All rights reserved.}


(plants were dried in an oven for $48 \mathrm{~h}$ at $60^{\circ} \mathrm{C}$ ). These traits were chosen for their importance in determining final crop yield and marketability and their speed and ease of measurement in a high-throughput assay. Because of the different growth habits of the lines used, relative values were then calculated by comparing stress treated plants to the control plant of each line in each replicate to allow comparison between the lines. For each variable, the five lines showing highest and lowest means were compared using Analysis of Variance (ANOVA, $P \leq 0.05$ ) to determine variation across the set of lines. Relative variable values were also used to assess the correlation of responses to the differing stresses using Pearson's correlation coefficient. $B$. oleracea cultivars were compared using unbalanced Analysis of Variance (ANOVA, $P \leq 0.05$ ). All statistical analyses were performed using GenStat 17th Edition software (VSN International Ltd, Hemel Hempstead, UK).

\section{RESULTS AND DISCUSSION}

B. oleracea lines were initially assayed for their tolerance to drought, flooding and salinity stress. A selection of nineteen lines exhibiting good levels of stress resistance (numbers 1, 8, 15, $20,24,25,27,29,32,37,43,46,47,52,54,64,66,69$ and 70) and one with high stress sensitivity (line 11) were then assayed for heat and cold tolerance. Across the set of lines used, the plants showed a range of tolerances to each of the stresses (an example is shown for relative fresh weight in Figure 1.). The five lines exhibiting the lowest and five lines exhibiting the highest means for each measured variable were determined (Tables 1 and 2). For each of the four variables recorded (relative fresh weight, relative dry weight, relative leaf number and relative height), there was a significant $(P \leq 0.05)$ difference in stress response between the low and high sets of five lines - in all cases except for relative leaf number in the heat stress experiment. This result agrees with our first hypothesis and indicates that the DFFS set of lines used in this study provide a suitably wide range of stress responses for use in assaying tolerance and for identifying promising genetic material for use in downstream breeding studies. The 
variables measured in all five stress assays showed strong positive correlation $(P \leq 0.001)$ apart from relative leaf number for the heat and cold assays, which did not correlate strongly with the other three variables (Pearson's correlation coefficient of 0.02-0.12).

Of the five most and least tolerant lines in each experiment (referred to as extreme lines), several were found to occur as extreme lines for multiple variables in response to a particular stress. For example, lines 5 and 68 were among the five most sensitive lines for all four measured variables for drought stress, while line 11 was among the five most sensitive lines for flooding stress. By comparison, line 15 was among the five most resistant lines for drought stress for relative fresh weight, relative dry weight and relative height, while lines 9, 28 and 35 were among the five most resistant lines for salinity stress for three different variables. For cold stress, lines 8 and 47 were among the five most resistant lines for all four variables and lines 52 and 70 for three variables. For heat stress, lines $8,46,47$ and 54 were among the five most tolerant lines for three variables. Interestingly, in some cases, the same line was found to be amongst the most sensitive and resistant lines for the same stress, depending on the variable measured. For example, line 15 is amongst the most sensitive to cold stress in terms of relative leaf number but amongst the most resistant for relative height, while line 66 is amongst the most sensitive for relative fresh weight and relative height, but amongst the most resistant for relative leaf number. This suggests that the control of leaf number in response to stress may be uncoupled from or in opposition to that of overall growth rate, with plants responding with either fewer, larger leaves or a greater number of smaller leaves.

Some lines also exhibited extreme responses to more than one stress (Table 2), agreeing with our second hypothesis, with a number of lines appearing to be resistant to multiple abiotic stresses, for example, line 15 was among the five most resistant lines for fresh weight for the drought, flooding and salinity stresses, while line 47 showed the same result for cold, drought and heat stress. As seen in Table 2, in most cases, the combination of stresses that each line was sensitive or resistant to was not consistent, providing no clear evidence that resistance to one stress is associated with resistance to additional stresses. Indeed, in the drought, flood and 
salinity assay, for each of the measured variables, no correlation between the different stresses was found to be greater than 0.5 . Some lines are found to be amongst the most resistant for some stresses yet amongst the most sensitive for others, for example, line 52 is amongst the most cold resistant but heat sensitive with regards to relative dry weight. However, line 47 is amongst the most resistant to both cold and heat in terms of relative dry weight, indicating that a tolerance of either heat or cold is not always associated with sensitivity towards the other. Tolerance of extremes of temperature appears to therefore take to form of either tolerance of one specific extreme at the expense of sensitivity towards the other extreme, or that tolerance to both extremes of temperature can also be observed.

For relative leaf number for the heat and cold assays, however, extreme lines were found to be largely the same for both stresses. For this subset of twenty lines, the data for relative leaf number showed a Pearson's correlation coefficient of $0.80(P \leq 0.001)$, indicating that lines able to produce leaves after heat stress are also able to do so after cold stress and could reflect a shared extreme temperature response. In addition, for the subset of lines also assayed for heat and cold tolerance, the response of relative dry weight showed a correlation $(0.51-0.58)$ between the drought, flood and salinity stresses, suggesting a possibility of underlying characteristics in this group of lines that infer tolerance to multiple stresses but the result is not clear and requires further investigation. On the whole, this suggests that tolerance to the different stresses requires different morphological and physiological characteristics and may reflect different underlying stress tolerance mechanisms. Some overlap between different stress response pathways in plants has been noted, such as the involvement of abscisic acid (ABA) in mediating responses to both drought and salinity stress, or the accumulation of misfolded proteins and reactive oxygen species in response to multiple stresses. ${ }^{21}$ However, while pathways responding to different stresses may utilise the same classes of signalling entities, such as MAP kinases or lipid molecules, the exact signals involved appear to be specific to each pathway. For example, the response pathways to different ionic stresses, while all signalling via cytosolic calcium signals, use specific sets of signalling proteins. ${ }^{21}$ B. oleracea lines which are tolerant to multiple stresses 
therefore may employ a number of different stress response mechanisms in different adverse conditions.

Genechip assays have been used to compare expression patterns to differentiate between heattolerant and heat-susceptible cabbage lines, showing that heat-tolerant lines show increased expression of heat shock proteins. ${ }^{3}$ Differential protein expression has also been noted in heat tolerant and heat sensitive cauliflower lines. ${ }^{11}$ Differential protein expression could also be responsible for variation in tolerance of other stresses, but is probably combined with morphological characteristics to determine the ultimate response of a particular line to each of the abiotic stress. Assaying protein expression could be used to screen genetically fixed lines, such as those investigated in this study, for stress tolerance and to provide more detailed analysis and to determine mature plant responses. However, such approaches may be prohibitively expensive and so whole plant seedling assays may provide a rapid lost-cost alternative but may not identify different responses in mature plants.

B. oleracea represents a number of different crop types that might be expected to behave differently under stress conditions. However, we found very little difference in stress tolerance between the different crop types. When the different $B$. oleracea crop types were compared, no significant differences in stress response for all five stresses assayed were found between the crop types. Abiotic stress tolerance in B. oleracea does not therefore appear to reflect differences between crop types, disagreeing with our third hypothesis. That the most broadly tolerant lines represent members of several different $B$. oleracea crop types is promising news for breeders looking to improve stress tolerance in different brassica crop types. It should be noted that due to the difficulty of producing genetically fixed lines, some crop types were under represented in the DFFS. However, the DFFS represents a unique resource to assess genetic variability for response to multiple stresses. Analysis of further lines of these crop types would be beneficial in future studies to confirm that there is no influence of crop type on B. oleracea abiotic stress tolerance. 
For some lines, periods of stress could prove beneficial. Mild abiotic stresses have the potential to be used for 'priming' plants to increase subsequent growth or stress tolerance, for example, hardening of transplants using low temperature or reduced irrigation prior to planting out in the field is commonly used to increase crop stress tolerance by activating plant stress responses, ${ }^{22-23}$ such as cryoprotective proteins. ${ }^{24}$ Such an approach has found promising results in a number of B. oleracea crops. ${ }^{23,}{ }^{25-28}$ However, different crop species or even cultivars may respond differently to stress and so require different hardening conditions. The method of hardening used can also affect results. Stress tolerance acquired by hardening can be lost (deacclimation) by subsequent periods of non-stressful conditions. ${ }^{29}$ Further investigation is required to determine if the short periods of stress provided by the assays used in this study could be used for priming to improve subsequent stress tolerance.

\section{CONCLUSIONS}

This paper demonstrates the value of the DFFS - which allows the same genotype to be screened against different environments in a controlled manner and therefore allows assessment of the genetic variation in stress response within B. oleracea. The results show that the lines of the DFFS exhibit a range of responses to the different stresses, agreeing with our first hypothesis. Such sets of lines therefore represent a useful resource for the identification of stress resistant genetic material for crop breeding programmes. Some lines showed resistance to multiple stresses, agreeing with our second hypothesis. Resistance was found to a maximum of three different stresses, however, no lines were found to be amongst the five most resistant lines for four or more stresses, raising implications for breeding for tolerance to different climatic extremes. In disagreement with our third hypothesis, abiotic stress tolerance in B. oleracea seedlings appears to be largely independent of crop type, which is an important result for developing more robust lines in multiple crops. In the field, abiotic stress is unlikely to occur solely as one particular type and likely represents a combination of factors e.g. heat and drought 
or coastal flooding and salinity. It will be interesting in the future to determine the response of the lines to multiple stresses applied at once and against longer term impositions of stress or stress applied at later growth stages. Tolerance of different stresses may result from different underlying mechanisms, yet with some lines exhibiting tolerance to multiple stresses, this suggests that multiple stress tolerance can be combined in a single line, providing the option of breeding multi-stress tolerant cultivars that may be better adapted to coping with a range of adverse conditions. Further studies will address if the stress tolerance noted in selected lines here provides either a shorter growth time to harvest or an increase in final yield. These results indicate that the options for breeding more robust B. oleracea lines in the future are varied and promising.

\section{ACKNOWLEDGEMENTS}

The authors wish to acknowledge the UK Government Department for Environment, Food and Rural Affairs (DEFRA) for funding this work as part of the Vegetable Genetic Improvement Network (VeGIN). This project was carried out in collaboration with the University of

Warwick Crop Centre, Wellesbourne, UK. The authors wish to thank Brian Thomas, Guy Barker, Graham Teakle, Charlotte Allender, Peter Walley and Jan Haycox for their assistance.

\section{REFERENCES}

1. Monaghan, JM, Daccache, A, Vickers, LH, Hess, TM, Weatherhead, EK, Grove, IG and Knox, JW, More 'crop per drop': constraints and opportunities for precision irrigation in European agriculture. J Sci Food Agric 93(5): 977-980 (2013).

2. Abou-Hussein, SD, Climate change and its impact on the productivity and quality of vegetable crops. J Appl Sci Res 4359-4383 (2012). 
3. Park, HJ, Jung, WY, Lee, SS, Song, JH, Kwon, SY, Kim, HR, Kim, CW, Ahn, JC and Cho, HS, Use of heat stress responsive gene expression levels for early selection of heat tolerant cabbage (Brassica oleracea L.). Int J Mol Sci 14: 11871-11894 (2013).

4. Rodriguez, VM, Soengas, P, Alonso-Villaverde, V, Sotelo, T, Cartea, ME and Velasco, P, Effect of temperature stress on the early vegetative development of Brassica oleracea L. BMC Plant Biology 15: 145 (2015).

5. Hadi. F, Ayaz, M, Ali, S, Shafiq, M, Ullah, R and Jan, AU, Comparative effect of polyethylene glycol and mannitol induced drought on growth (in vitro) of canola (Brassica napus), cauliflower (Brassica oleracea) and tomato (Lycopersicum esculentum) seedlings. Int J Biosci 4: 34-41 (2014).

6. Hnilickova, H, and Duffek, J, Water deficit and its effect on physiological manifestations in selected varieties of cauliflower (Brassica oleracea var. botrytis L.). Scientia Agric Bohemica 35: 57-63. (2004).

7. Kage, H, Kochler, $M$ and Stutzel, H, Root growth and dry matter partitioning of cauliflower under drought stress conditions: measurement and simulation. Eur $J$ Agronomy 20(4): 379-394 (2004).

8. Issarakraisila, M, Qifu, M and Turner, RW, Photosynthetic and growth responses of juvenile Chinese kale (Brassica oleracea var. alboglabra) and Caisin (Brassica rapa subsp. parachinensis) to waterlogging and water deficit. Scientia Hort 111: 107-113 (2007).

9. Higashio, H, Aizawa, S, Kunihisa, M, Murakami, K, Tokuda, S and Uragami, A. Evaluation for comparison of waterlogging tolerance based on anaerobic respiration reaction of root in lettuce and broccoli. Hort Res (Japan) 11(4): 477-483 (2012).

10. Chen, PH, Hsieh, MH, and Lo, HF, Physiological response of cabbage (Brassica oleracea L. var capitata) to high temperature and waterlogging. J Taiwan Soc Hort Sci 60(4): 265-286 (2014). 
11. Lin, $\mathrm{KH}, \mathrm{Chen}, \mathrm{LFO}, \mathrm{Li}, \mathrm{SD}$ and Lo, HF, Comparative proteomic analysis of cauliflower under high temperature and flooding stresses. Scientia Hort 183: 118-129. (2015).

12. Zhu, SY, Zhang, XL, Luo, TK, Liu, Q, Tang, Z and Jing, ZG, Effects of NaCl stress on seed germination, early seedling growth and physiological characteristics of cauliflower (Brassica oleracea L. var. botrytis L.). African J Biotech 10: 17940-17947 (2011).

13. Batool, A, Ashraf, M, Akram, NA and Al-Qurainy, F, Salt-induced changes in the growth, key physicochemical and biochemical variables, enzyme activities, and levels of non-enzymatic anti-oxidants in cauliflower (Brassica oleracea L.) J Hort Sci Biotech 88: 231-241 (2013).

14. Giuffrida, F, Scuderi, D, Giurato, R and Leonardi, C, Physiological response of broccoli and cauliflower as affected by $\mathrm{NaCl}$ salinity. Acta Hort 1005: 435-441 (2013).

15. Wahid, A, Fazal, H and Jan, AU, In vitro assessment of tomato (Lycopersicum esculentum) and cauliflower (Brassica oleracea) seedlings growth and proline production under salt stress. Int J Biosci 4: 109-115 (2014).

16. Shannon, MC, Grieve, CM, Lesch, SM and Draper, JH, Analysis of salt tolerance in nine leafy vegetables irrigated with saline drainage water. J Am Soc Hort Sci 125: 658$664(2000)$.

17. Jamil, M, Lee, DB, Jung, KY, Ashraf, M, Lee, SC, and Rha, ES, Effect of salt ( $\mathrm{NaCl})$ stress on germination and early seedling growth of four vegetables species. J Central Eur Agric 7: 273-281 (2006).

18. Jamil, M, Lee, KB, Jung, KY, Lee, DB, Han, MS and Rha, ES, Salt stress inhibits germination and early seedling growth in cabbage (Brassica oleracea capitata L.) Pak $J$ Biol Sci 10: 910-914 (2007a).

19. Jamil, M, Shafiq, R and Rha, ES, Salinity effect on plant growth, PSII photochemistry and chlorophyll content in sugar beet (Beta vulgaris L.) and cabbage (Brassica oleracea capitata L.). Pak J Bot 39: 753-760 (2007b). 
20. Gao, RY, Effects of three salt stresses on the seed sprouting and seedling growth of cabbage. J Henan Agric Sci 40: 121-123 (2011).

21. Zhu, JK, Abiotic stress signalling and responses in plants, Cell, 167(2): 313-324 (2016).

22. Stavang, JA, Hansen, M and Olsen, JE, Short term temperature drops do not enhance cold tolerance. Plant Growth Reg. 55(3): 199-206 (2008).

23. Kalisz, A, Cebula, S, Kunicki, E, Gil, J, Sekara, A and Grabowska, A, Effect of chilling stress before transplanting on morphological variables of broccoli heads. Acta Sci PolHort Cultus 13: 129-139 (2014).

24. Sieg, F, Schrider, W, Schmitt, JM and Hincha, DK, Purification and characterization of a cryoprotective protein (cryoprotectin) from the leaves of cold-acclimated cabbage. Plant Physiol 111(1): 215-221 (1996).

25. Bogdanova, NS and Adritskaya, NA, The effect of different hardening conditions on head cabbage and cauliflower transplants. Zapiski Leningradskogo S.-Kh. Instituta 292: 34-39 (1976).

26. Rutherford, PP and Whittle, R, Changes in sucrose levels as an indicator of the marketable quality of cauliflowers exposed to freezing temperatures. Scientia Hort 14(2): 117-123 (1981).

27. Fuller, MP, Varietal differences in frost hardiness of cauliflower. Aspects Appl Biol 34: 179-182 (1993).

28. Atici, O, Demir, Y and Kocacaliskan, I, Effects of low temperature on winter wheat and cabbage leaves. Biol Plantarum 46: 603-606 (2003).

29. Sasaki, H, Ichimura, K, Imada, S and Oda, M. Loss of freezing tolerance associated with decrease in sugar concentrations by short term deacclimation in cabbage seedlings. J Jap Soc Hort Sci 70: 294-298 (2001). 


\section{TABLES}

Table 1. The five most sensitive and resistant lines for each variable for each stress assayed. In each case the five most resistant and five most sensitive lines for each variable for each of the five stresses is shown. In the case of the cold and heat stress, a subset of twenty of the initial sixty five lines was assayed. Line DFFS number is given together with crop type.

\begin{tabular}{|c|c|c|c|c|c|c|c|c|c|}
\hline Treatment & Tolerance & $\begin{array}{l}\text { Line and } \\
\text { crop } \\
\text { type } \\
\end{array}$ & $\begin{array}{l}\text { Relative } \\
\text { FW (\%) }\end{array}$ & $\begin{array}{l}\text { Line and } \\
\text { crop } \\
\text { type } \\
\end{array}$ & $\begin{array}{l}\text { Relative } \\
\text { DW (\%) }\end{array}$ & $\begin{array}{l}\text { Line and } \\
\text { crop } \\
\text { type } \\
\end{array}$ & $\begin{array}{c}\text { Relative } \\
\text { leaf no. } \\
(\%) \\
\end{array}$ & $\begin{array}{l}\text { Line and } \\
\text { crop } \\
\text { type } \\
\end{array}$ & $\begin{array}{c}\text { Relative } \\
\text { height } \\
(\%)\end{array}$ \\
\hline \multirow{11}{*}{ Drought } & \multirow{5}{*}{ Sensitive } & $23(b)$ & 50.7 & $5(b)$ & 45.9 & $23(b)$ & 66.7 & $5(b)$ & 69.8 \\
\hline & & $5(b)$ & 55.2 & $23(b)$ & 46.4 & $68(\mathrm{~g})$ & 74.1 & 7 (i) & 69.8 \\
\hline & & 11 (i) & 56.1 & $68(\mathrm{~g})$ & 48.1 & $54(\mathrm{ca})$ & 80.5 & $68(\mathrm{~g})$ & 83.4 \\
\hline & & $68(\mathrm{~g})$ & 57.9 & 34 (b) & 50.3 & 5 (b) & 81 & 8 (i) & 83.9 \\
\hline & & 26 (i) & 59.3 & $59(x)$ & 56.4 & 8 (i) & 81 & G (ca) & 84.9 \\
\hline & & & & & & & & & \\
\hline & \multirow{5}{*}{ Resistant } & 15 (i) & 129.6 & 69 (ca) & 123.9 & $42(b)$ & 108.9 & $20(b)$ & 119.5 \\
\hline & & $67(b)$ & 112.4 & 15 (i) & 119.2 & $\mathrm{G}(\mathrm{ca})$ & 108.5 & 15 (i) & 118.2 \\
\hline & & 37 (ca) & 107.5 & $32(b)$ & 112.7 & 51 (i) & 105.6 & 16 (i) & 113.5 \\
\hline & & 47 (ca) & 106.6 & 51 (i) & 109.3 & $36(\mathrm{ac})$ & 105.1 & $57(\mathrm{al})$ & 111.8 \\
\hline & & 35 (i) & 106 & 70 (i) & 107.3 & 35 (i) & 104.8 & $\mathrm{G}(\mathrm{ca})$ & 111.4 \\
\hline \multirow{11}{*}{ Flooding } & \multirow{6}{*}{ Sensitive } & 11 (i) & 60 & 49 (b) & 54.4 & 11 (i) & 91.7 & 11 (i) & 79.4 \\
\hline & & 50 (i) & 70.2 & $5(b)$ & 54.6 & $18(b)$ & 91.7 & 48 (i) & 85.2 \\
\hline & & 18 (b) & 71.5 & 11 (i) & 62.8 & $57(\mathrm{al})$ & 92.6 & 18 (b) & 85.8 \\
\hline & & 55 (i) & 86 & 7 (i) & 71.2 & $5(b)$ & 94.4 & 7 (i) & 86.3 \\
\hline & & 30 (i) & 86.4 & 53 (b) & 72.6 & 70 (i) & 94.4 & 50 (i) & 87.8 \\
\hline & & & & & & & & & \\
\hline & \multirow{5}{*}{ Resistant } & 15 (i) & 133.7 & 69 (ca) & 147.4 & $71(b)$ & 123.8 & 46 (i) & 118.8 \\
\hline & & $\mathrm{G}(\mathrm{ca})$ & 125.7 & 45 (i) & 137.4 & $42(b)$ & 119.6 & $\mathrm{G}(\mathrm{ca})$ & 118.4 \\
\hline & & $59(\mathrm{x})$ & 121 & 27 (ca) & 127.9 & $40(\mathrm{ac})$ & 116.7 & 41 (b) & 116.9 \\
\hline & & 46 (i) & 119.7 & $66(\mathrm{al})$ & 126.1 & $60(\mathrm{x})$ & 112.5 & 15 (i) & 115.1 \\
\hline & & 41 (b) & 115.3 & 29 (i) & 126 & 27 (ca) & 110.3 & $\mathrm{~N}(\mathrm{ac})$ & 113.2 \\
\hline \multirow{9}{*}{ Salinity } & \multirow{5}{*}{ Sensitive } & 51(i) & 2.2 & 51 (i) & 7.5 & 51 (i) & 44.4 & $52(\mathrm{ca})$ & 33.5 \\
\hline & & $12(b)$ & 9.8 & $52(\mathrm{ca})$ & 11.1 & $52(\mathrm{ca})$ & 47.2 & 51 (i) & 42.7 \\
\hline & & $52(\mathrm{ca})$ & 15.6 & $12(b)$ & 12.3 & $12(b)$ & 57.5 & 66 (al) & 45.3 \\
\hline & & 1 (b) & 19.8 & $1(b)$ & 19.4 & $43(b)$ & 62.5 & $12(b)$ & 50.2 \\
\hline & & 5 (b) & 28.1 & 7 (i) & 23.6 & 1 (b) & 63 & $1(b)$ & 51.5 \\
\hline & \multirow{4}{*}{ Resistant } & 35 (i) & 97.8 & $28(\mathrm{~g})$ & 93.4 & 9 (al) & 100 & 35 (i) & 100.1 \\
\hline & & 15 (i) & 92.3 & 69 (ca) & 88.1 & 19 (i) & 100 & 57 (al) & 95.6 \\
\hline & & 17 (b) & 91.2 & 35 (i) & 80.5 & $28(\mathrm{~g})$ & 100 & 9 (al) & 95.1 \\
\hline & & $28(\mathrm{~g})$ & 88.5 & 54 (ca) & 80.4 & 38 (i) & 100 & 38 (i) & 94.6 \\
\hline
\end{tabular}




\begin{tabular}{|c|c|c|c|c|c|c|c|c|c|}
\hline & & $9(\mathrm{al})$ & 85.8 & 15 (i) & 78.4 & $40(\mathrm{ac})$ & 97 & 17 (b) & 93.4 \\
\hline & & 27 (ca) & 26.4 & 27 (ca) & 19.9 & 64 (al) & 90.5 & 27 (ca) & 55.4 \\
\hline & & 29 (i) & 30.3 & 29 (i) & 33.1 & 29 (i) & 91.7 & 29 (i) & 70.3 \\
\hline & Sensitive & 66 (al) & 44.2 & $32(b)$ & 48.9 & 15 (i) & 92.9 & $66(\mathrm{al})$ & 71.1 \\
\hline & & $32(b)$ & 50.4 & 24 (i) & 50.3 & $43(b)$ & 94.4 & $32(b)$ & 73.9 \\
\hline & & 24 (i) & 52.7 & $66(\mathrm{al})$ & 50.9 & 25 (i) & 95.8 & 24 (i) & 76.9 \\
\hline \multicolumn{10}{|l|}{ Cold } \\
\hline & & 47 (ca) & 125.7 & 47 (ca) & 125.1 & $66(\mathrm{al})$ & 110.3 & 47 (ca) & 106.7 \\
\hline & & 8 (i) & 104.5 & 8 (i) & 106.9 & 20 (b) & 109.5 & 70 (i) & 105.7 \\
\hline & Resistant & 25 (i) & 103.2 & 70 (i) & 104.3 & 8 (i) & 104.8 & 15 (i) & 102.7 \\
\hline & & $52(\mathrm{ca})$ & 102.8 & $52(\mathrm{ca})$ & 101.7 & 54 (ca) & 104.2 & $52(\mathrm{ca})$ & 101.7 \\
\hline & & 70 (i) & 100.4 & 25 (i) & 100.1 & 47 (ca) & 103.7 & 8 (i) & 101 \\
\hline & & $43(b)$ & 74.4 & $43(b)$ & 67 & 25 (i) & 95.8 & 43 (b) & 84.8 \\
\hline & & 29 (i) & 86.4 & 52 (ca) & 78.9 & 15 (i) & 100 & 29 (i) & 91.4 \\
\hline & Sensitive & 69 (ca) & 89.1 & 15 (i) & 81 & 64 (al) & 100 & 11 (i) & 94.8 \\
\hline & & $1(b)$ & 89.4 & $1(b)$ & 84.1 & 29 (i) & 112.5 & 27 (ca) & 97 \\
\hline & & 11 (i) & 90.2 & 27 (ca) & 84.3 & 43 (b) & 123.6 & $64(\mathrm{al})$ & 97.6 \\
\hline \multicolumn{10}{|l|}{ Heat } \\
\hline & & 54 (ca) & 116.3 & 54 (ca) & 137.6 & $66(\mathrm{al})$ & 115.9 & 25 (i) & 111.1 \\
\hline & & 47 (ca) & 115 & 70 (i) & 122.3 & 54 (ca) & 108.3 & 8 (i) & 110.9 \\
\hline & Resistant & 70 (i) & 111.7 & 46 (i) & 110.9 & 8 (i) & 104.8 & 24 (i) & 105.6 \\
\hline & & 46 (i) & 108.7 & 47 (ca) & 109.1 & $20(b)$ & 104.8 & 46 (i) & 105.2 \\
\hline & & 8 (i) & 107 & 24 (i) & 103.1 & 47 (ca) & 103.7 & $52(\mathrm{ca})$ & 104.4 \\
\hline
\end{tabular}

Mean values $(n=3)$ are given for each variable, calculated relative to untreated control plants. $\mathrm{FW}=$ fresh weight, $\mathrm{DW}=$ dry weight, no. $=$ number. $\mathrm{G}=$ greyhound cabbage, $\mathrm{N}=$ nero di Toscana kale. Crop types are as follows: B oleracea var. acephala (ac), var. alboglabra (al) var. botrytis (b), var. capitata (ca), var. costata (co), var. gongylodes (g), var. italica (i) and a hybrid derived from cross between a var. alboglabra x italica parent and a var. capitata parent (x). 
Table 2. Lines occurring amongst the five most and least tolerant lines for multiple stresses. For each of the four measured variables, lines which occur amongst the five most sensitive or resistant lines for two or more stresses are indicated with line number and crop type. In the case of the cold and heat stress, a subset of twenty of the initial sixty five lines was assayed.

\begin{tabular}{|c|c|c|c|c|c|c|c|c|}
\hline \multirow[b]{2}{*}{ Tolerance } & \multicolumn{2}{|c|}{ Relative FW (\%) } & \multicolumn{2}{|c|}{ Relative DW (\%) } & \multicolumn{2}{|c|}{ Relative leaf no. (\%) } & \multicolumn{2}{|c|}{ Relative height (\%) } \\
\hline & $\begin{array}{l}\text { Line and } \\
\text { crop type }\end{array}$ & Stress & $\begin{array}{l}\text { Line and } \\
\text { crop type }\end{array}$ & Stress & $\begin{array}{l}\text { Line and } \\
\text { crop type }\end{array}$ & Stress & $\begin{array}{l}\text { Line and } \\
\text { crop type }\end{array}$ & Stress \\
\hline \multirow{6}{*}{ Sensitive } & 1 (b) & $\mathrm{H}, \mathrm{S}$ & 1 (b) & $\mathrm{H}, \mathrm{S}$ & 5 (b) & $\mathrm{D}, \mathrm{F}$ & 7 (i) & $\mathrm{D}, \mathrm{F}$ \\
\hline & 5 (b) & $\mathrm{D}, \mathrm{S}$ & 5 (b) & $\mathrm{D}, \mathrm{F}$ & 15 (i) & $\mathrm{C}, \mathrm{H}$ & 11 (i) & $\mathrm{F}, \mathrm{H}$ \\
\hline & 11 (i) & $\mathrm{D}, \mathrm{F}, \mathrm{H}$ & 7 (i) & $\mathrm{F}, \mathrm{S}$ & 25 (i) & $\mathrm{C}, \mathrm{H}$ & 27 (ca) & $\mathrm{C}, \mathrm{H}$ \\
\hline & 29 (i) & $\mathrm{C}, \mathrm{H}$ & 27 (ca) & $\mathrm{C}, \mathrm{H}$ & 29 (i) & $\mathrm{C}, \mathrm{H}$ & $66(\mathrm{al})$ & $\mathrm{C}, \mathrm{S}$ \\
\hline & & & 52 (ca) & $\mathrm{H}, \mathrm{S}$ & 43 (b) & $\mathrm{C}, \mathrm{H}, \mathrm{S}$ & & \\
\hline & & & & & 64 (al) & $\mathrm{C}, \mathrm{H}$ & & \\
\hline \multirow{7}{*}{ Resistant } & 8 (i) & $\mathrm{C}, \mathrm{H}$ & 15 (i) & $\mathrm{D}, \mathrm{S}$ & 8 (i) & $\mathrm{C}, \mathrm{H}$ & 8 (i) & $\mathrm{C}, \mathrm{H}$ \\
\hline & 15 (i) & $\mathrm{D}, \mathrm{F}, \mathrm{S}$ & 47 (ca) & $\mathrm{C}, \mathrm{H}$ & 20 (b) & $\mathrm{C}, \mathrm{H}$ & 15 (i) & $\mathrm{C}, \mathrm{D}, \mathrm{F}$ \\
\hline & 35 (i) & $\mathrm{D}, \mathrm{S}$ & 54 (ca) & $\mathrm{H}, \mathrm{S}$ & $40(\mathrm{ac})$ & $\mathrm{F}, \mathrm{S}$ & 46 (i) & $\mathrm{F}, \mathrm{H}$ \\
\hline & 46 (i) & $\mathrm{F}, \mathrm{H}$ & 69 (ca) & $\mathrm{D}, \mathrm{F}, \mathrm{S}$ & 42 (b) & $\mathrm{D}, \mathrm{F}$ & $52(\mathrm{ca})$ & $\mathrm{C}, \mathrm{H}$ \\
\hline & 47 (ca) & $\mathrm{C}, \mathrm{D}, \mathrm{H}$ & 70 (i) & $\mathrm{C}, \mathrm{D}, \mathrm{H}$ & 47 (ca) & $\mathrm{C}, \mathrm{H}$ & 57 (al) & $\mathrm{D}, \mathrm{S}$ \\
\hline & 70 (i) & $\mathrm{C}, \mathrm{H}$ & & & 54 (ca) & $\mathrm{C}, \mathrm{H}$ & $\mathrm{G}(\mathrm{ca})$ & $\mathrm{D}, \mathrm{F}$ \\
\hline & & & & & $66(\mathrm{al})$ & $\mathrm{C}, \mathrm{H}$ & & \\
\hline
\end{tabular}

$\overline{\mathrm{FW}}=$ fresh weight, $\mathrm{DW}=$ dry weight, no. = number. $\mathrm{C}=$ cold, $\mathrm{D}=$ drought, $\mathrm{F}=$ flooding, $\mathrm{H}=$ heat, $\mathrm{S}=$ salinity, $\mathrm{G}=$ greyhound cabbage. Crop types are as follows: B oleracea var. acephala (ac), var. alboglabra (al) var. botrytis (b), var. capitata (ca), var. costata (co), var. gongylodes (g), var. italica (i) and a hybrid derived from cross between a var. alboglabra $\mathrm{x}$ italica parent and a var. capitata parent (x).

This article is protected by copyright. All rights reserved. 


\section{FIGURES}

Figure 1.

Relative fresh weight of the B. oleracea lines assayed for responses to the five abiotic stresses.

65 lines were tested for tolerance of (A) drought, (B) flooding and (C) salinity stress, with a subset of 20 lines then being tested for tolerance of (D) heat and (E) cold stress. Error bars represent $+/$ - one standard error of the mean (SEM).

This article is protected by copyright. All rights reserved. 


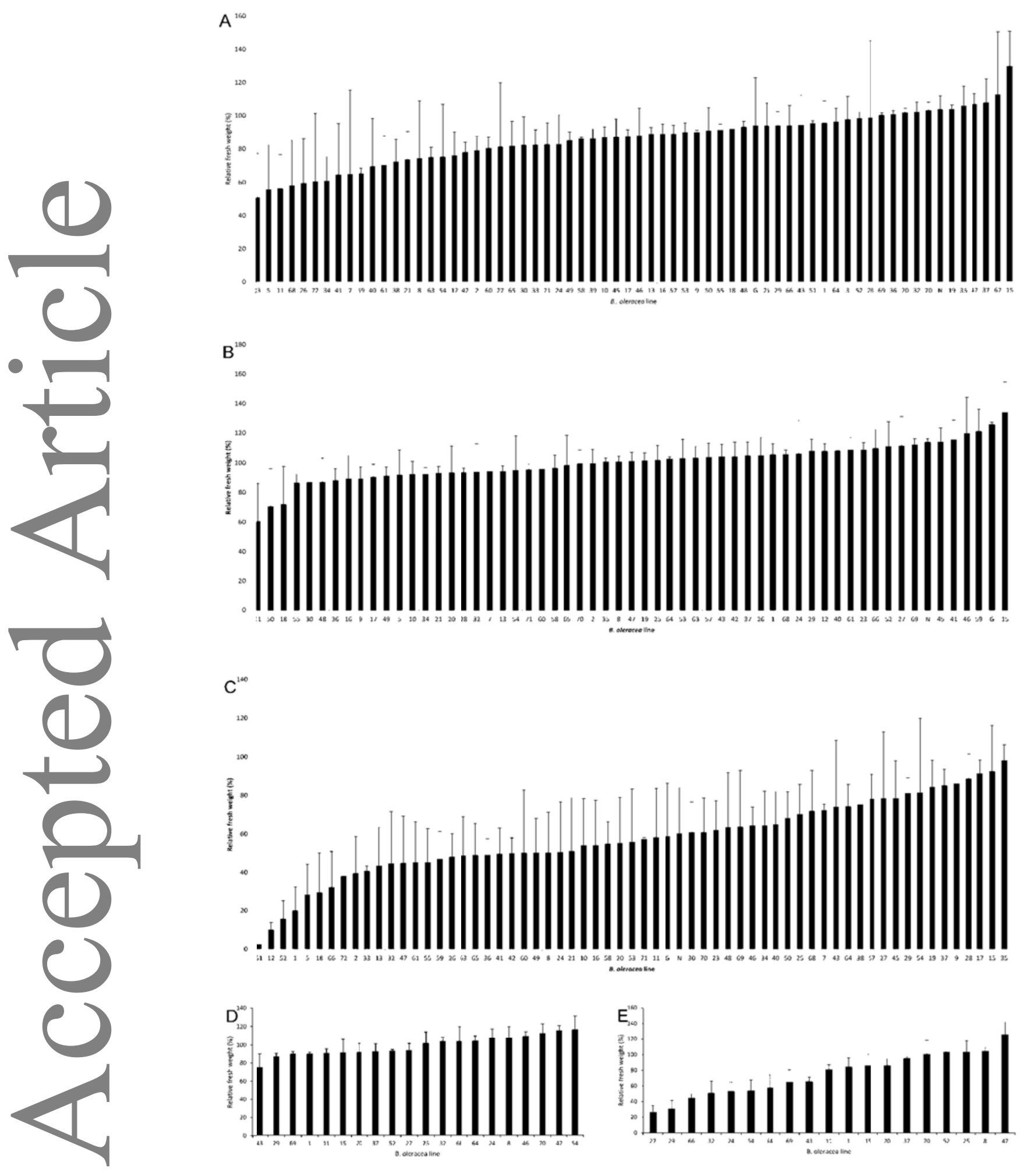

This article is protected by copyright. All rights reserved. 